\title{
LICENCIAMENTO AMBIENTAL MUNICIPAL: UMA ANÁLISE DOS CRITÉRIOS APRECIADOS PELOS ÓRGÃOS MUNICIPAIS
}

\author{
MUNICIPAL ENVIRONMENTAL PERMIT: AN ANALYSIS OF THE CRITERIA ASSESSED
}

\author{
Luane Borges Machadoa, Severino Soares Agra Filhoa \\ aUniversidade Federal da Bahia \\ luane.b.machado@gmail.com,severino@ufba.br
}

Submissão: 27 de março de 2021 Aceitação: 27 de outubro de 2021

\section{Resumo}

O licenciamento ambiental é um instrumento preventivo de controle de atividades e de empreendimentos efetivamente ou potencialmente poluidores, visando garantir a qualidade do meio ambiente. A lei complementar no 140/11 (BRASIL, 2011) definiu ser de competência dos Municípios a aplicação desse instrumento quando os potenciais impactos ambientais se limitarem ao âmbito local. Diante da importância da municipalização do licenciamento ambiental, a presente pesquisa objetivou analisar as práticas aplicadas no processo de licenciamento ambiental municipal na Bahia. O estudo focou especificamente a etapa de apreciação, pelos órgãos municipais, das informações referentes ao empreendimento proposto disponibilizadas pelos requerentes de licenças ambientais. A metodologia da pesquisa constitui-se de estudos de caso de três municípios no Estado da Bahia com práticas consolidadas no licenciamento ambiental e consistiu na realização de entrevistas com os técnicos de seus respectivos órgãos ambientais e na identificação dos critérios de apreciação utilizados no processo de concessão das licenças. Os resultados obtidos evidenciaram que não há uma análise substantiva das pressões ambientais decorrentes das intervenções propostas nem um estudo de sua compatibilidade com a capacidade do meio ambiente em assimilá-las. A devida avaliação de impactos ambientais é inexistente nos processos de licenciamento estudados nesta pesquisa. A conclusão é que esse importante instrumento ambiental tem sido subutilizado por se limitar a uma análise procedimental restrita à aferição de restrições normativas elementares. Portanto, compromete o alcance de seu objetivo de prevenção e controle da degradação ambiental, contrariando os objetivos da política nacional e estadual de meio ambiente.

Palavras-Chave: Licenciamento Ambiental Municipal; Procedimentos de Licenciamento Ambiental; Avaliação de Impactos; Gestão Ambiental Municipal

\section{Abstract}

Environmental Permit is a preventive instrument for controlling activities and undertakings that are actually or potentially polluting, aiming to guarantee the quality of the environment. Complementary Law ํㅜ 140/11 (BRASIL, 2011) defined that it is incumbent upon the Municipalities to apply this instrument when potential environmental impacts are limited to the local scope. Given the importance of municipalization of environmental licensing, this research aimed to analyze the practices applied in the municipal environmental permit process in Bahia to identify its potentialities, its technical and institutional weaknesses and operational aspects. The study focused specifically on the study of the assessment stage of municipal bodies on the information regarding the project proposal made available by applicants for environmental licenses. The research methodology consists of case studies of three municipalities in the State of Bahia which have consolidated practices in environmental licensing and consisted of interviews with technicians from their respective environmental bodies and identification of the appraisal criteria used in the license concession process. The obtained results showed that there is no substantive analysis of the environmental pressures resulting from the proposed interventions, nor a study of their compatibility with the environment's ability to assimilate them. The proper assessment of environmental impacts does not exist in the licensing processes 
studied in this research. The conclusion is that this important environmental instrument has been underused because it is limited to a procedural analysis restricted to the measurement of elementary normative restrictions. Therefore, it compromises the achievement of its objective of preventing and controlling environmental degradation and contradicts the objectives of the national and state environmental policy.

Keywords: Municipal Environmental Permit; Environmental Permit Process; Impact Assessment; Municipal Environmental Management

\section{INTRODUÇÃO}

O licenciamento ambiental é um instrumento de gestão da Política Nacional do Meio Ambiente, instituída pela lei federal $\mathrm{n}^{\circ}$ 6.938, de 1981 (BRASIL, 1981). Segundo Milaré (2011), o licenciamento ambiental corresponde à atuação pública no controle sobre as ações humanas que possam provocar impactos ao meio ambiente. Corroborando com esse pensamento, Farias (2015) defende que esse instrumento é um processo administrativo complexo exercido pela instância responsável pela gestão ambiental, seja no âmbito federal, estadual ou municipal, buscando assegurar a qualidade de vida da população por meio de um controle prévio e o permanente acompanhamento das atividades capazes de causar degradação ao meio ambiente. Após as controvérsias sobre a inserção municipal, a lei complementar ํㅡ 140/11 (BRASIL, 2011) definiu como competência dos municípios o licenciamento ambiental de empreendimentos e atividades capazes de causar impactos ambientais de âmbito local, conforme tipologias definidas pelos respectivos Conselhos Estaduais de Meio Ambiente observados os critérios de porte, potencial poluidor e natureza da atividade, além daqueles localizados em unidades de conservação instituídas pelo próprio município.

Diante da crescente municipalização do licenciamento ambiental, emergiram diversas dificuldades e questionamentos, sobretudo em relação à perspectiva analítica envolvida nas apreciações feitas. De acordo Nascimento e Fonseca (2016), os órgãos licenciadores municipais ainda enfrentam diversos problemas institucionais e políticos, com destaque para limitação de recursos financeiros, de infraestrutura e de pessoal, a baixa capacidade técnica, existência de interferências políticas e de interesses econômicos nos processos. O Tribunal de Contas da União (BRASIL, 2007) considera a padronização dos procedimentos do licenciamento ambiental como um desafio, por entender que diferentes perspectivas na análise e instrução de processos podem gerar um excesso de discricionariedade no órgão ambiental, comprometendo a qualidade e eficiência do licenciamento ambiental. A Associação Nacional de Órgãos Municipais em Meio Ambiente ANAMMA (2009 apud IPEA, 2013) considera que um dos principais problemas do licenciamento ambiental e que resulta em uma ameaça à sua aplicação no âmbito municipal é esse instrumento tornar-se cartorial, com um fim em si mesmo. Por outro lado, a elaboração de padrões e normas específicas para os procedimentos e critérios técnicos e metodológicos adotados no processo de licenciamento pode prover maior agilidade e rigor nas exigências da sustentabilidade ambiental, além de maior transparência para o requerente da licença e para a sociedade (REGANHAN et al., 2013).

O processo de licenciamento ambiental é complexo e compreende muitos estudos por parte do requerente da licença e do órgão ambiental. Os procedimentos conduzidos $e$ as informações requeridas são fundamentais para a avaliação do alcance preventivo da gestão ambiental, evitando que o processo de licenciamento se reduza a um mero cumprimento formal e burocrático. Como argumenta Agra Filho (2014), para cumprir seus propósitos preventivos, o processo de licenciamento ambiental deve apreciar previamente uma atividade ou empreendimento, avaliando as possibilidades de compatibilidade entre os seus potenciais impactos adversos e as condições ambientais existentes, e observando as restrições e as diretrizes de sustentabilidade estabelecidas para o local ou região e/ou capacidade de suporte dos recursos ambientais envolvidos. O referido autor defende que a apreciação sobre o deferimento ou não de uma licença ambiental deve confrontar o potencial de intervenção da atividade ou empreendimento com as condições de resiliência e vulnerabilidade ambiental do local. O potencial de intervenção da atividade consiste em suas diversas ações modificadoras do ambiente, sendo consideradas as medidas de minimização ou de mitigação. A 
análise da capacidade de resiliência e vulnerabilidade ambiental vai apreciar as condições dos sistemas ambientais, principalmente os aspectos relacionados à sua capacidade de assimilar as interferências decorrentes da atividade proposta.

Para se lograr os propósitos de tal análise, é fundamental que os órgãos ambientais, em sua apreciação do processo de licenciamento, atentem para as informações requeridas e considerem os critérios e o referencial analítico pertinente à avaliação dos impactos ambientais potenciais. Como adverte Struchel (2016), as questões ambientais não podem ser avaliadas como um teorema matemático no qual uma operação resultará numa inquestionável consequência precisa e objetiva. Este autor ressalta que a apreciação pelos órgãos licenciadores deve considerar conceitos como: impactos cumulativos, sinergia, resiliência, sucessão ecológica, funções ecológicas e serviços ecossistêmicos, essenciais para a compreensão do meio natural, para os quais, em geral, não existem orientações normativas que possam abranger qualquer localidade. Na mesma linha de raciocínio, Sanches (2008) enfatiza a necessidade de se buscar a relação entre as intervenções ambientais previstas pelo projeto e a vulnerabilidade do meio, visando à avaliação do impacto da atividade ou empreendimento sobre o local selecionado. Para Sadler (1996), na avaliação dos potenciais impactos ambientais de um projeto, deve-se atentar para conceitos básicos visando conhecer o contingente de recursos próprios dos sistemas do ambiente e quais suas condições de assimilação de resíduos, levando em consideração a preservação da biodiversidade, a capacidade de suporte e a carga crítica dos recursos naturais. Nessa perspectiva, esse mesmo autor considera que a avaliação de impacto ambiental envolve duas componentes analíticas: uma análise procedimental e uma análise substantiva. A análise procedimental tem um cunho operacional e de aferição do atendimento normativo e dos requerimentos estabelecidos. A análise substantiva envolve a apreciação de conteúdo técnico que analisa as informações do projeto da atividade e a sua compatibilidade com os objetivos preventivos e com as diretrizes de sustentabilidade da qualidade ambiental. Assim sendo, a análise substantiva consiste na etapa técnica crucial, a que possibilita uma avaliação do potencial de impacto bem como o alcance do papel preventivo do projeto. É a fase determinante para a tomada de decisão sobre a concessão de uma licença ambiental.

Agra Filho (2014) destaca a importância de se apreciar os projetos sob a ótica da melhor tecnologia disponível como sendo este outro critério relevante para a avaliação preventiva no processo de licenciamento ambiental e, portanto, um requisito indispensável na incorporação da perspectiva da sustentabilidade. Como defendem Marinho e colaboradores (2012) o licenciamento ambiental é um instrumento de gestão ambiental com o papel de exigir e promover práticas e tecnologias com ênfase na produção limpa, aumentando a ecoeficiência dos processos de produção e dos produtos e reduzindo os riscos para o ambiente e os seres vivos. Desse modo, o objetivo preventivo e regulador do licenciamento ambiental se materializaria no planejamento e na definição da melhor alternativa tecnológica, minimizando as alterações nas condições ambientais.

O sistema normativo do Estado da Bahia, em seu decreto estadual no 14.024/2012 (BAHIA, 2012), no artigo nำ104, prevê a análise do mérito dos projetos submetidos ao licenciamento ambiental do seguinte modo:

Art. 104. A apreciação do pedido de licença ambiental deve considerar como mérito de análise os seguintes critérios, simultaneamente:

I - a aplicação da melhor tecnologia disponível, adotando-se os princípios da produção mais limpa;

II - a sustentabilidade socioambiental do empreendimento ou atividade;

III - a eliminação ou mitigação dos impactos ambientais adversos, a potencialização dos impactos ambientais positivos, bem como medidas compensatórias para os impactos não mitigáveis;

IV - a clareza da informação e a confiabilidade dos estudos ambientais;

V - a contextualização do empreendimento ou atividade na unidade territorial na qual se insere, a exemplo de bacia hidrográfica, bioma, território de identidade, dentre outros;

VI- o potencial de risco à segurança e à saúde humana. (BAHIA, 2012)

Diante das considerações indicadas na literatura especializada, evidencia-se que a 
apreciação do requerimento do licenciamento ambiental envolve a análise de elementos do projeto e a sua compatibilização com os requisitos normativos referentes às restrições ambientais estabelecidas, além das especificidades de cada localidade. Isso exige critérios de avaliação mais substantivos que possam detectar os potenciais impactos e as possíveis intervenções nas componentes biofísicas e socioeconômicas de determinada proposta de atividade. A análise substantiva deve ser baseada na satisfatoriedade das informações e na possibilidade das medidas previstas em relação ao atendimento aos objetivos de prevenção e à sustentabilidade pretendida. $\mathrm{O}$ seu conteúdo técnico integra o escopo da discricionariedade e da responsabilidade das instituições públicas.

As apreciações dos requerimentos de licenciamento ambiental realizadas pelos órgãos licenciadores no Brasil carecem de estudos relativos ao mérito da avaliação, bem como de critérios e diretrizes para fundamentar o processo decisório, sobretudo na esfera municipal. Por essa razão, faz-se necessário o desenvolvimento de estudos que possam analisar a prática do licenciamento ambiental nos municípios e os desafios na sua aplicação, visando avaliar a efetividade de prevenção alcançada. Nessa perspectiva, 0 objeto deste estudo foi 0 licenciamento ambiental, que foi analisado quanto à suficiência da avaliação dos potenciais impactos ambientais, tendo como base os critérios de apreciação das licenças emitidas.

\section{METODOLOGIA}

Pelo fato de o objeto deste estudo envolver procedimentos analíticos e decisões de órgãos ambientais municipais, o que necessariamente exige apreciações subjetivas, a abordagem desta pesquisa foi qualitativa, com a utilização de estudos de caso. Consideraram-se os seguintes aspectos na esfera dos municípios: arcabouço legal e procedimentos de apreciação de licenciamento ambiental, incluindo os pareceres dos órgãos licenciadores, com o propósito de refletir sobre a seguinte questão: "Como as práticas aplicadas no processo de licenciamento ambiental na esfera municipal têm contribuído para avaliação dos potenciais impactos ambientais de empreendimentos propostos, garantindo a qualidade ambiental do município?"

Para o desenvolvimento deste trabalho, foram utilizados os seguintes procedimentos metodológicos: levantamento bibliográfico, pesquisa documental, elaboração de categorias analíticas, análise documental e aplicação de entrevistas semiestruturadas. Foram selecionados municípios que possuem as melhores capacidades institucionais para o licenciamento e que se enquadram no mesmo nível de capacidade definida no Estado da Bahia pela Resolução Cepram no 3.427/2013 (BAHIA, 2013). Esta resolução classifica os municípios em três níveis: Nível 01, Nível 02 e Nível 03. Um município está classificado como Nível 03 quando possui melhor capacidade institucional e competência para licenciar. Foram selecionados municípios de Nível 03 , os quais supostamente teriam uma melhor estrutura de gestão e, consequentemente, estariam mais capacitados para exercer o licenciamento ambiental. Considerou-se que os casos selecionados representariam os melhores resultados que o licenciamento municipal tem alcançado.

Nos órgãos ambientais dos referidos municípios, foram selecionados processos de licenciamento ambiental mais recentes (no período de 2012 a 2017) de empreendimentos que pudessem representar a realidade das análises técnicas praticadas. Essa seleção visou a que houvesse aspectos comuns nesses processos de maneira a permitir uma análise comparativa entre eles. As atividades mais frequentes são as da construção civil de loteamento residenciais e as destinadas a projetos industriais.

Para a obter as informações usadas na pesquisa, duas etapas foram seguidas: i) o levantamento prévio de informações sobre o sistema de licenciamento dos municípios selecionados e os seus instrumentos legais e normativos relativos ao tema, os seus procedimentos de licenciamento ambiental, bem como as orientações, os manuais e guias disponíveis aos interessados. Também foram utilizadas as informações disponibilizadas pelos próprios órgãos municipais, incluindo cópias de alguns de seus processos de licenciamento ambiental. ii) análise dos pareceres, identificandose os critérios apreciados que levaram ao deferimento da licença ambiental e suas condicionantes ambientais. Essas informações foram complementadas por meio de entrevistas com os técnicos dos órgãos ambientais municipais, visando esclarecer e validar a compreensão sobre as informações previamente levantadas. Para a identificação dos critérios considerados relevantes, a pesquisa utilizou a 
seguinte base analítica:

" As informações solicitadas pelos órgãos municipais e fornecidas pelos requerentes de licenças ambientais. Na prática existente, os órgãos municipais estabelecem um roteiro básico de informações por tipologias de atividades.

" As informações e apreciações contidas nos pareceres dos processos de licenciamento ambiental identificadas com os critérios de avaliação utilizados pelos órgãos municipais, observando-se a abordagem das seguintes categorias de análise: a) potencial de intervenção ambiental da atividade ou empreendimento; b) condições ou vulnerabilidade do ambiente e sua capacidade de suporte; e c) a apreciação apresentada sobre a compatibilidade das pressões do empreendimento e seus potenciais impactos com as condições ambientais do local proposto.

Considerou-se que a obtenção de uma licença ambiental requer a apresentação aos órgãos municipais de documentos, estudos e projetos que subsidiem a apreciação das intervenções propostas e suas implicações no local selecionado, assim como o potencial de intervenção das atividades propostas e a sua compatibilidade com normas vigentes e com as condições ambientais existentes. Foi considerada ainda a consistência dos pareceres com as condicionantes da licença expedida. Por meio da análise dos pareceres, os processos de licenciamento selecionados foram identificados e qualificados quanto à sua suficiência. Ademais, buscou-se identificar se o licenciamento ambiental foi utilizado como um instrumento de promoção de práticas e tecnologias que atendam aos princípios da produção limpa e da ecoeficiência dos processos, de minimização e de estímulo ao uso de recursos renováveis e não nocivos e à preservação da biodiversidade.

Conforme evidenciado nas práticas existentes e na aplicação da Produção Mais Limpa (BRASIL, 2007; AGRA FILHO, 2012; MARINHO et al., 2010, 2012; KIPERSTOK et al., 2002), para se avaliar o gerenciamento ambiental de uma atividade é necessário que o requerente apresente, entre outros dados básicos: os tipos e as vazões dos efluentes líquidos, bem como sua caracterização, os resíduos gerados, seu quantitativo, a fonte de sua geração, a sua classificação, as formas de seu manejo, oportunidades de seu reaproveitamento ou de sua redução e a sua destinação final. Quanto ao consumo de água, é essencial que os requerentes apresentem as fontes de fornecimento, o quantitativo necessário e seus usos, de modo que o órgão municipal possa fazer uma apreciação e identificar melhorias em sua ecoeficiência.

Em relação ao processo produtivo e às operações previstas, considera-se fundamental para a instalação de uma atividade industrial a apresentação de um fluxograma que especifique a mensuração dos fluxos de insumos e de matériasprimas, a especificação dos produtos finais, suas formas de armazenamento e manejo, os seus riscos e perigos, assim como o quantitativo do consumo de água, seus usos e os resíduos gerados. É também necessário que haja informações sobre o consumo de energia para se identificar potenciais medidas de ecoeficiência no sistema produtivo. Sem a obtenção desses dados, perde-se a oportunidade de se promover a prática da Produção Limpa. A partir dessas considerações, analisou-se a suficiência das informações fornecidas pelos requerentes, enquadrando-as nas seguintes categorias:

" Suficiente: as informações fornecidas pelo requerente permitiram analisar o potencial de intervenção do empreendimento, as características do local selecionado e suas condições de resiliência e vulnerabilidade ambiental (fornecimento de todas as informações necessárias para se mensurar a intensidade e/ou magnitude da atividade pretendida e para uma avaliação do seu potencial de impacto e a aplicação das medidas necessárias;

" Insuficiente parcial: as informações, qualitativas e quantitativas, fornecidas pelo requerente permitiram apenas uma análise parcial do potencial de intervenção do empreendimento, pois dados fundamentais não foram apresentados (fornecimento de parte das informações solicitadas e algumas de conteúdo qualitativo sem elementos passíveis de mensuração, comprometendo a devida avaliação sobre o potencial de impacto e a aplicação das medidas necessárias);

" Insuficiente precário: as informações fornecidas foram apresentadas de forma genérica e meramente protocolar, sem descrições ou justificativas técnicas (fornecimento somente de algumas informações solicitadas, descrição geral qualitativa, sem elementos passíveis de mensuração, comprometendo a devida 
avaliação sobre o potencial de impacto e a aplicação das medidas necessárias);

" Omissa: nenhuma informação foi fornecida ou abordada sobre $o$ aspecto analisado.

A etapa de apreciação e elaboração dos pareceres técnicos é o momento em que o órgão ambiental deve proceder a análise substantiva das intervenções propostas, e das medidas previstas, visando a uma avaliação dos seus potenciais impactos adversos e a sua compatibilidade às normas e aos padrões de qualidade ambiental. Espera-se que essa apreciação avalie também as oportunidades de aplicação dos princípios da produção limpa. Uma apreciação técnica e as diretrizes de análise do órgão licenciador devem culminar numa avaliação que resultará no deferimento ou não da licença ambiental. Nesse sentido, foram consideradas as determinações preconizadas na legislação estadual vigente (BAHIA, 2012) e os elementos necessários para a análise substantiva recomendada pela bibliografia especializada, destacando-se: Kiperstok e colaboradores (2002), Agra Filho (2012), Marinho e colaboradores (2010, 2012), Hofmann (2015), Sánchez (2008), Reganhan e colaboradores (2013), Montaño e Souza (2008), entre outros autores.

O procedimento metodológico consistiu em analisar as informações contidas nos pareceres emitidos e na identificação dos critérios de apreciação empregados nos processos de licenciamento ambiental expedidos pelos órgãos municipais. Para cada aspecto e cada elemento utilizado como critério de apreciação das informações fornecidas foi atribuída uma avaliação, observando-se as seguintes condições de suficiência:

" Suficiente: as considerações sobre as informações fornecidas e apreciações abordadas no parecer foram suficientemente abrangentes e pertinentes ao mérito dos aspectos em análise. A apreciação deve ser devidamente circunstanciada em relação às adequações e capacidade de controle das medidas propostas para os impactos previstos e a sua compatibilidade com as condições ambientais apresentadas;

" Insuficiente parcial: as considerações e apreciações abordadas ficaram restritas à análise de algumas informações qualitativas e algumas quantitativas relativas à mensuração de alguns potenciais impactos. Poucas medidas estão previstas, e outras fundamentais ficaram omissas, ou seja, a apreciação é incompleta em relação aos impactos previstos e sem considerações objetivas sobre a pertinência da medida proposta;

" Insuficiente precário: as considerações sobre as informações fornecidas e as apreciações abordadas nos pareceres foram genéricas e meramente qualitativas, sem qualquer análise relativa à mensuração dos potenciais impactos $\mathrm{e}$ às medidas previstas, limitando-se a um resumo do que foi apresentado pelo requerente;

" Omissa: nenhuma consideração ou apreciação foi apresentada sobre os aspectos analisados.

Para a definição das condições adotadas nas análises dos casos estudados foram adaptados e utilizados os procedimentos aplicados por Scherer (2011), Sánchez (2008), Montaño e colaboradores (2014) e Almeida e colaboradores (2012).

\section{RESULTADOS E DISCUSSÃO}

Em conformidade à metodologia descrita, serão apresentados a seguir os resultados e as discussões das análises da prática do licenciamento ambiental nos municípios estudados e as tipologias de atividades selecionadas para cada critério de análise considerado. Conforme o procedimento descrito na metodologia, foram analisadas as informações solicitadas pelos órgãos municipais e fornecidas pelos requerentes de licenças ambientais.

\section{a. Análise das informações solicitadas e fornecidas pelos requerentes de licenças ambientais}

A partir da sistematização da análise das informações fornecidas pelos requerentes foram obtidos os resultados indicados nas figuras apresentadas a seguir. Os dados expostos nas figuras 1 e 2 consolidam as informações solicitadas e fornecidas em relação às atividades: industrial (operações e equipamentos existentes, água, energia, insumos gerais e matérias-primas, 
produtos finais, efluentes líquidos, resíduos sólidos, emissões gasosas, risco de acidentes e drenagem) e da construção civil (água, energia, efluentes líquidos, resíduos sólidos, emissões gasosas, risco de acidentes e drenagem), e indicam que estes seriam suficientes para uma avaliação do potencial de intervenção dos empreendimentos pelo órgão municipal. Nas figuras 3 e 4, são apresentados os resultados relativos à caracterização ambiental (ordenamento do solo, ocupação do entorno, socioeconômica, infraestrutura local, áreas protegidas, subsolo e nível d'água, cobertura vegetal, clima, recursos hídricos e geomorfologia. As figuras 5 e 6 mostram os resultados referentes aos potenciais impactos $\mathrm{e}$ as medidas mitigadoras propostas.

Figura 1 - Informações fornecidas pelos requerentes sobre o potencial de intervenção do empreendimento - Processos de Tipologia Indústria

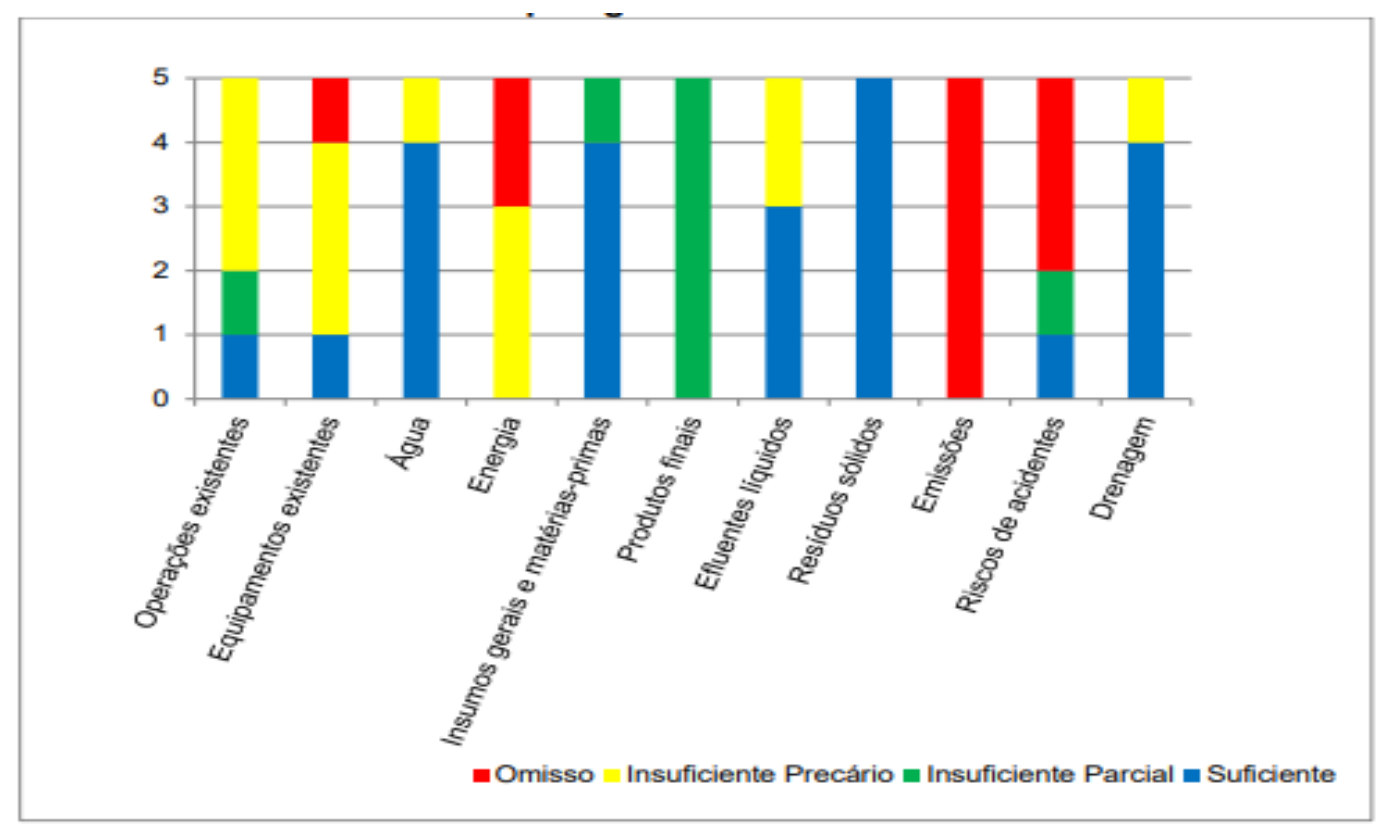

Fonte: os autores.

Figura 2 - Informações fornecidas pelos requerentes sobre o potencial de intervenção do empreendimento - Processos de Tipologia Construção Civil

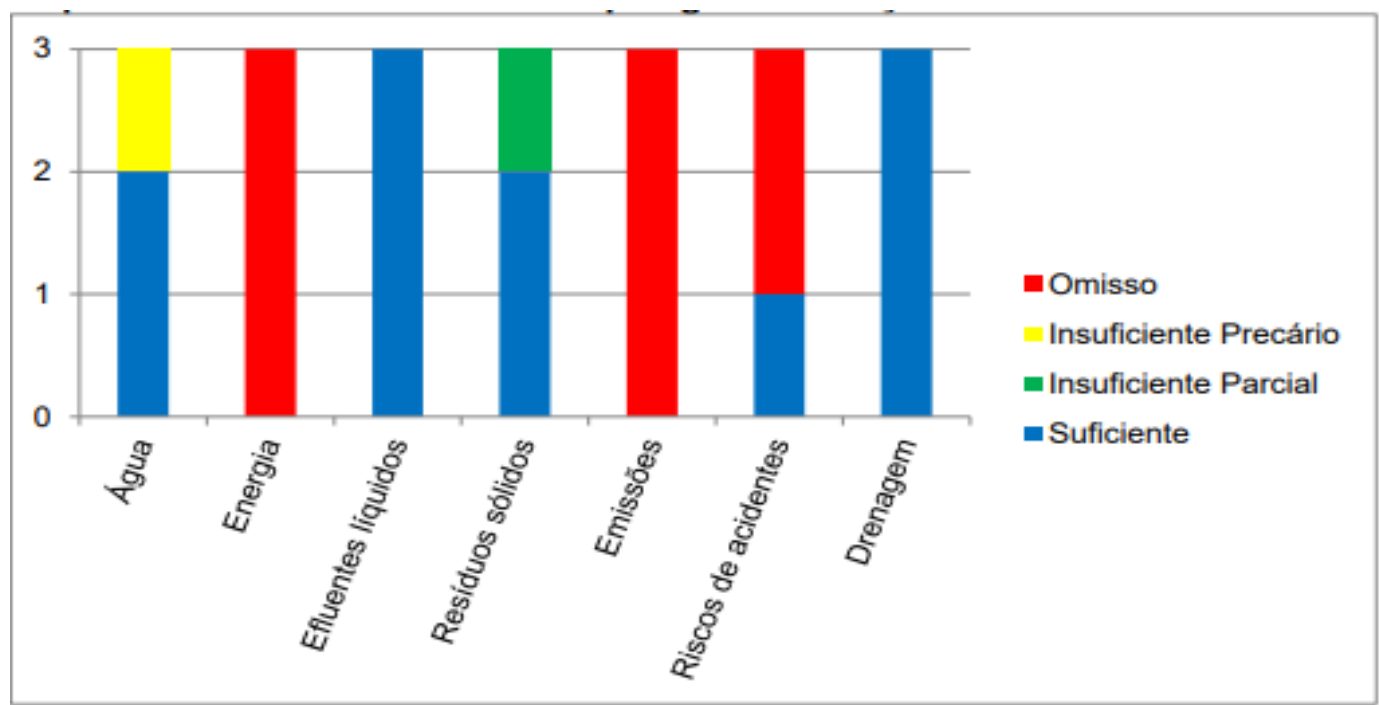

Fonte: os autores. 
Diante dos resultados sistematizados nas figuras 1 e 2, observa-se uma predominância de insuficiências ou omissões de informações, destacando-se aquelas que se referem ao consumo de energia, às emissões e ao risco de acidentes. Nas atividades industriais, a suficiência de informações restringe-se aos resíduos sólidos e, na maioria dos casos, ao que se refere aos insumos gerais e produtos, ao de consumo de água, efluentes líquidos e ao sistema de drenagem. Os dados obtidos sugerem que 0 processo produtivo não é considerado pelos órgãos municipais como sendo um aspecto fundamental a ser analisado durante a apreciação sobre o licenciamento ambiental de uma indústria. Cabe ressaltar que as descrições insuficientes dos processos produtivos das indústrias analisadas dificultam a devida análise dos seus sistemas de produção, impedindo a identificação de medidas relativas à ecoeficiência.

Em geral, os resultados evidenciam que as informações fornecidas foram insuficientes para a mensuração das potenciais intervenções que os empreendimentos possam gerar, tornando impossível se realizar uma apreciação técnica substantiva. Os dados apresentam também fragilidades e inconsistências para a realização da devida análise procedimental. Desse modo, a necessária avaliação do potencial de intervenção do empreendimento no local selecionado fica comprometida.

Quanto à caracterização ambiental do local pretendido, as informações solicitadas devem permitir ao órgão ambiental a compreensão das condições ambientais e das vulnerabilidades da área de intervenção e da área sob a sua influência, abrangendo as componentes biofísicas e socioeconômicas. Isso visa possibilitar a análise da interação dos componentes ambientais com as intervenções propostas e potenciais impactos decorrentes. São informações imprescindíveis para a consistência da fase posterior, quando os proponentes devem informar a sua compreensão sobre a compatibilização do empreendimento com a capacidade do ambiente de comportar a intervenção proposta. Assim, é necessário que o requerente apresente informações sobre o local selecionado e sua área de influência com o levantamento da cobertura vegetal e da fauna, sobre possíveis interferências em áreas protegidas, sobretudo as de preservação permanente, a descrição dos recursos hídricos superficiais e subterrâneos, dentre outras pertinentes ao local. Ademais, vale destacar a importância de que sejam descritos os ambientes construídos nos casos de empreendimentos a serem instalados em áreas já urbanizadas do entorno a ser ocupado. Os resultados das informações fornecidas estão consolidados nas figuras 3 e 4 .

Os resultados apresentados na figura 3 mostram uma predominância na omissão de informações nas atividades industriais analisadas, exceto em relação às que estão em áreas protegidas. Isso evidencia que a caracterização ambiental não é considerada determinante na apreciação dos requerimentos das licenças dessa tipologia. Essa constatação sugere que a análise das potenciais intervenções ambientais dessas atividades se restringem ao atendimento normativo vigente sobre as áreas protegidas. Em relação às atividades de construção civil, observase que as informações fornecidas foram em geral suficientes na maioria dos aspectos analisados. As insuficiências de informações foram relativas à socioeconomia, a recursos hídricos, clima e geomorfologia.

Figura 3 - Informações fornecidas pelos requerentes, sobre a caracterização ambiental do local proposto - Processos de Tipologia Indústria

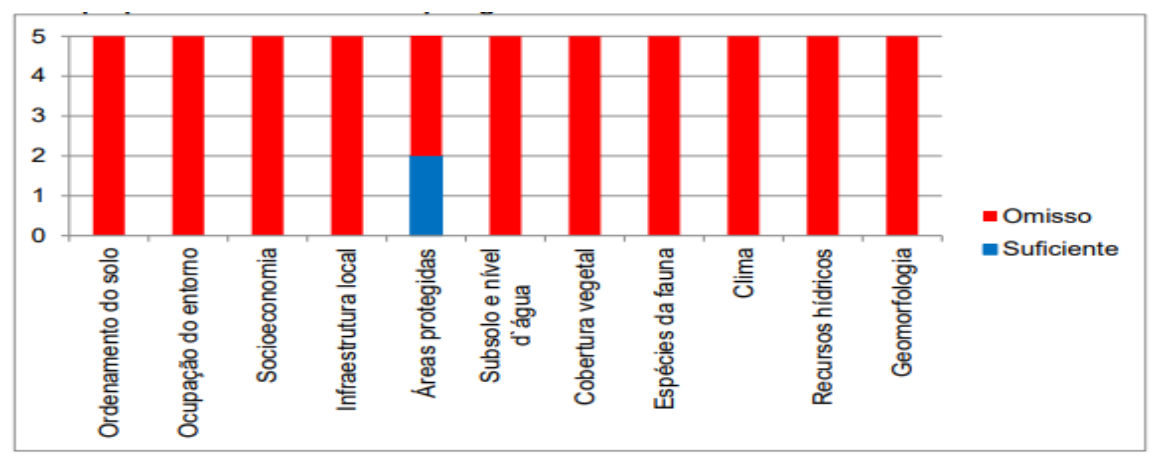

Fonte: os autores. 
Figura 4 - Informaçõesfornecidas pelos requerentes, sobre a caracterização ambiental do local proposto - Processos de Tipologia Construção Civil

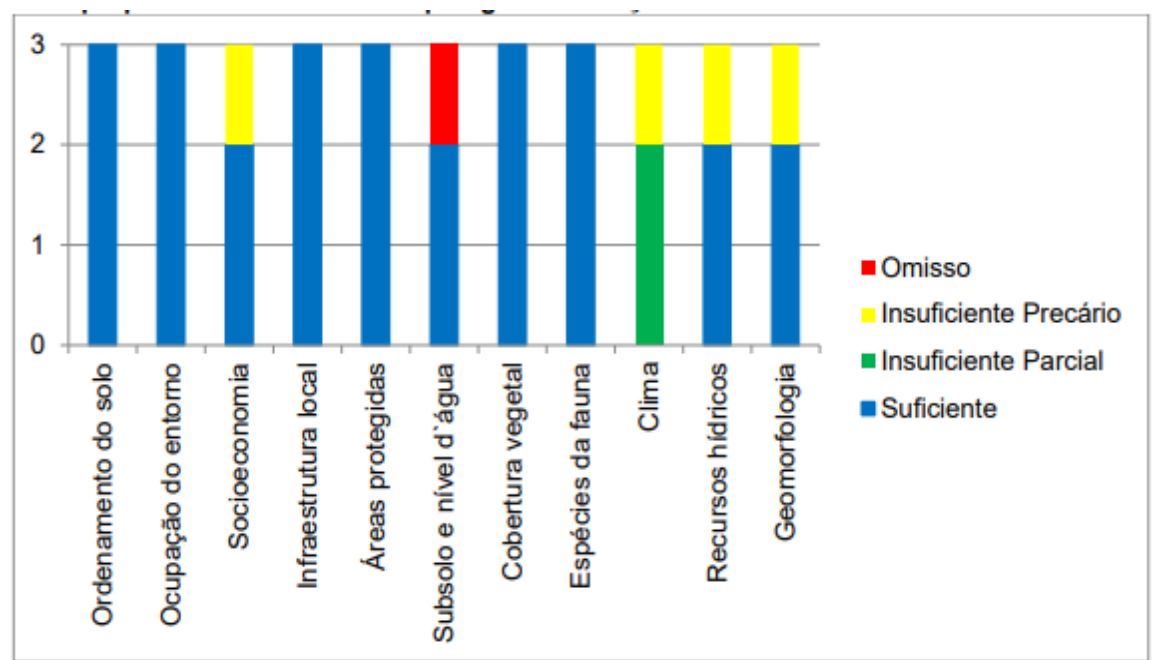

Fonte: os autores.

Os resultados sobre a caracterização ambiental indicam que as apreciações das informações fornecidas se restringem à aferição do atendimento de requisitos normativos vigentes, o que torna a apreciação meramente cartorial. Em relação à avaliação substantiva dos potenciais impactos dessas atividades, ela é totalmente omissa.

A apreciação das informações relativas aos potenciais de impactos e medidas mitigadoras previstas são indispensáveis para a apreciação dos órgãos municipais sobre a potencial compatibilidade da intervenção proposta com as condições ambientais. Para que isso se concretize, os requerentes devem fornecer as especificações básicas relativas aos potenciais impactos ambientais do empreendimento e os possíveis resultados das medidas de prevenção, mitigação, controle e monitoramento a serem adotadas para cada impacto identificado. Nesse sentido, essas informações foram solicitadas. Incluíram-se os dados referentes ao tratamento de efluentes líquidos gerados, ao gerenciamento de resíduos sólidos, ao controle de emissões e aos sistemas de segurança. Os resultados sobre as informações. fornecidas foram sistematizados na figura 5 .

Figura 5 - Informações sobre os potenciais impactos e as medidas mitigadoras propostas

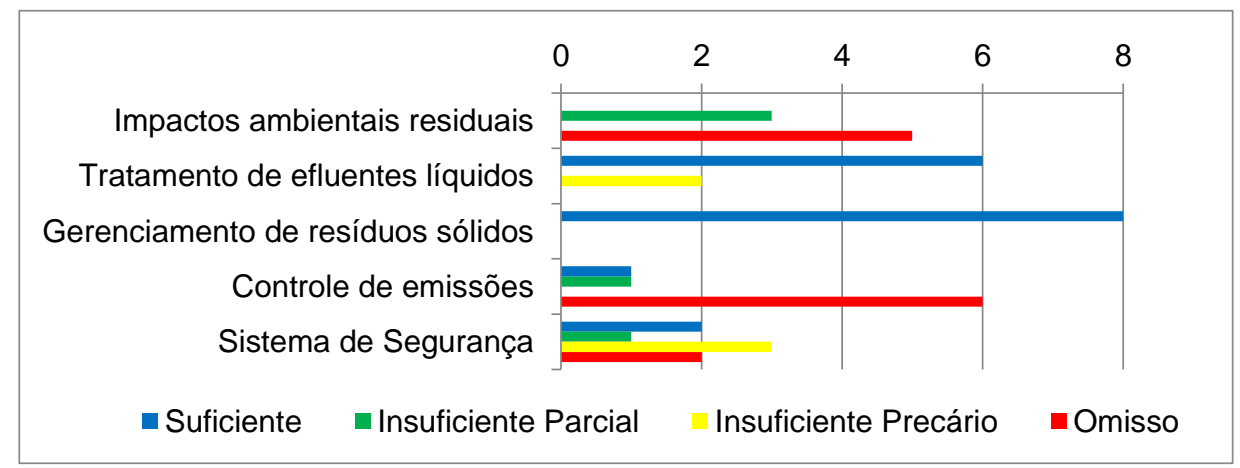

Fonte: os autores.

Os resultados relativos aos potenciais impactos mostram que as informações dadas se referiam apenas às atividades da construção civil, e foram enquadradas como parcialmente insuficientes. Em relação às medidas previstas, as informações relativas ao gerenciamento dos resíduos sólidos foram suficientes para ambas as atividades. Em geral, o que prevalece são informações parcialmente incompletas com alguns impactos ambientais apresentados e outros 
omitidos. Os resultados denotam que as informações fornecidas se restringem principalmente à indicação de medidas de gerenciamento de resíduos e efluentes líquidos, sugerindo que a análise dos requisitos normativos vigentes é privilegiada, em detrimento da apreciação de alternativas técnicas, tecnológicas e operacionais visando a uma maior ecoeficiência produtiva.

Diante desse quadro, pode-se afirmar que as informações fornecidas pelos requerentes de licenças ambientais não permitem que os órgãos ambientais municipais apreciem adequadamente as mensurações relativas às pressões e ações impostas no meio ambiente pelas intervenções propostas, desse modo também impossibilitam que os potenciais impactos que elas podem ocasionar sejam avaliados. Isso sugere que essas informações não são vistas como determinantes para as análises realizadas. Esse fato pode ser associado à baixa complexidade que essas atividades geralmente representam, assim como à infraestrutura de serviços geralmente disponíveis nas áreas urbanas, suscitando uma condução de mera aferição de requisitos normativos convencionais vigentes. Contudo, uma análise substantiva das medidas de controle exigiria verificar a sua pertinência e avaliar a suficiência das informações prestadas para cada condição ambiental.

\section{b. Análise dos pareceres e critérios de apreciação identificados}

As análises dos pareceres e seus resultados foram consolidados nas figuras a seguir apresentadas. Os resultados visando à análise do potencial de intervenção do empreendimento são apresentados na figura 6 .

Figura 6 - Critérios apreciados nos pareceres sobre o potencial de intervenção do empreendimento Caracterização do Empreendimento

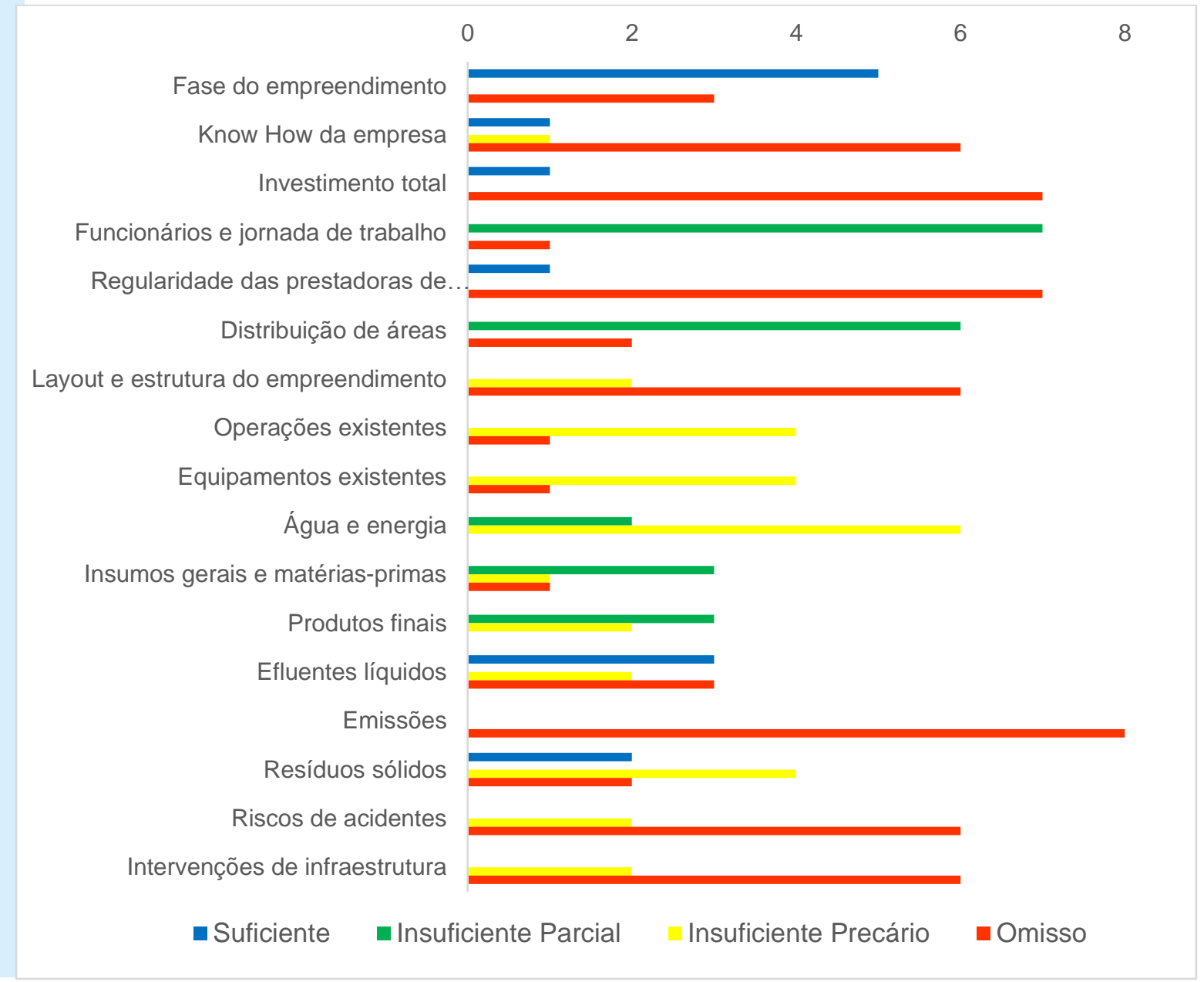

Fonte: os autores. 
Conforme os resultados obtidos, na sua maioria, os pareceres apresentam-se predominantemente na condição de insuficiência precária ou de omissão, bem como são meramente informativos repetindo informações apresentadas pelo próprio requerente sobre os aspectos: operações existentes, equipamentos, insumos gerais e matérias-primas, produtos, água, energia, riscos de acidente e drenagem. Observase também que as abordagens relativas às operações consistem apenas na indicação resumida das etapas dos processos produtivos sem qualquer apreciação e que as análises das informações são omissas, mesmo em processos em que os requerentes apresentam dados qualitativos. Em relação ao consumo de água e energia, por exemplo, os pareceres técnicos se limitavam a apresentar fontes de abastecimento e a conferir a viabilidade de fornecimento das suas respectivas concessionárias.

A suficiência das apreciações foi restrita aos itens efluentes líquidos (em 3 atividades da construção civil) e resíduos sólidos (em 2 atividades da construção civil). Constata-se que as condições de insuficiências foram mais expressivas nos pareceres das atividades industriais. Denota-se uma relação direta das apreciações com a fragilidade no fornecimento de informações e que estas só atingiram a categoria de suficiência nos aspectos que dispõem de normas ou requisitos estabelecidos. Assim, podese afirmar que a análise ficou atrelada a uma abordagem meramente procedimental de aferição das normas existentes ou dos padrões preestabelecidos. Caberia destacar ainda que, embora as informações sobre os resíduos sólidos tenham sido suficientes, observa-se que, nos pareceres emitidos pelos órgãos municipais, as apreciações são insuficientes, pois seu conteúdo se restringiu a indicar a destinação dos resíduos, sem apreciar a estimativa de seu quantitativo e uma possível minimização de sua geração.

Os resultados da apreciação sobre a caracterização ambiental do local proposto estão expostos na figura 7.

Figura 7 - Critérios apreciados nos pareceres sobre a caracterização ambiental do local proposto

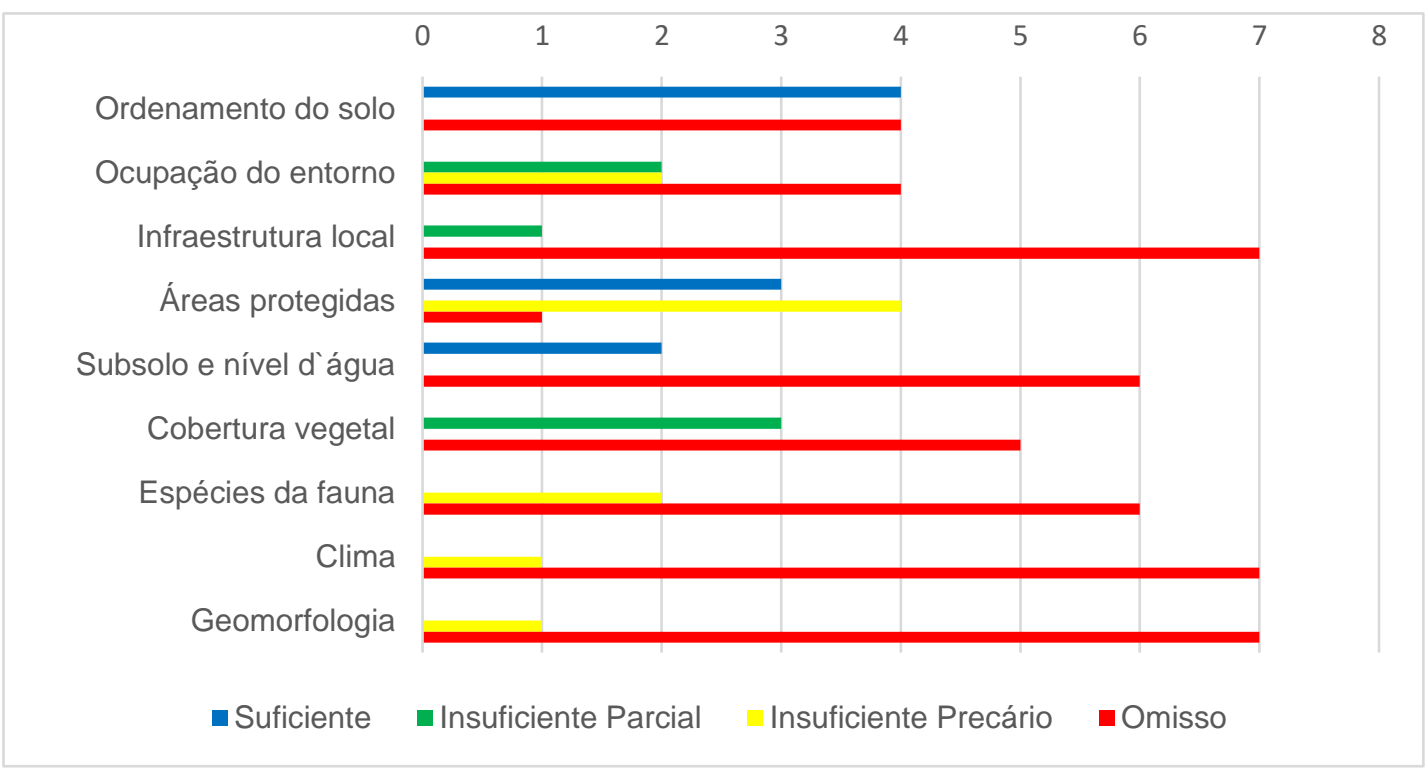

Fonte: os autores.

Conforme os perfis dos dados consolidados indicam, há uma expressiva predominância de condições de omissão de aspectos ou de insuficiências nas apreciações que constam nos pareceres. As considerações suficientes constantes nos pareceres se restringem ao ordenamento do solo e às áreas protegidas, ou seja, a uma aferição de exigências normativas existentes. Nos pareceres dos processos de tipologia indústria, a abordagem sobre a caracterização ambiental do local proposto é restrita à indicação dos dados fornecidos sobre as áreas ocupadas e protegidas, entre outras, sem qualquer 
apreciação. A condição de suficiência é observada, minimamente, na apreciação do ordenamento do solo (em 2 atividades da construção civil e em 1 industrial), de áreas protegidas (em 3 atividades da construção civil) e de nível d'água (em 2 atividades industriais). Nas considerações sobre a compatibilidade do empreendimento com o ordenamento do uso do solo, verifica-se que as leis municipais relativas a esse aspecto e aos planos de desenvolvimento urbano são observadas. Isso sugere que a apreciação quanto à caracterização ambiental limita-se à identificação de alguma restrição legal. Ressaltam-se ainda as insuficiências encontradas quanto às considerações relativas à cobertura vegetal e às espécies da fauna. $A$ apreciação nos pareceres se reduz a um breve resumo do que foi apresentado pelo requerente nos roteiros de caracterização do empreendimento, informando as espécies encontradas ou a situação de antropização do local, com pouca ou nenhuma conclusão quanto ao diagnosticado.

Diante dessas observações, percebe-se uma lacuna relevante quanto à análise das condições de resiliência e vulnerabilidade ambiental, uma vez que não há apreciações relacionadas às interferências propostas. As avaliações negligenciam os dados sobre a caracterização ambiental, principalmente em relação às atividades industriais, tornando-a algo formal e precariamente atrelado aos aspectos sobre os quais há normas ou requisitos estabelecidos. Denota-se, portanto, uma abordagem restrita, de aferição, ou seja, uma análise meramente procedimental de cunho cartorial.

Os resultados da análise dos pareceres e apreciações sobre os potenciais impactos dos empreendimentos e as medidas mitigadoras propostas estão consolidados e apresentados na figura 8. Os pareceres sobre esses aspectos devem compreender a análise essencialmente substantiva do confronto das apreciações das intervenções previstas com a caracterização ambiental analisada. Esse procedimento é determinante para a fundamentação do parecer conclusivo da licença requerida. Entretanto, os resultados sistematizados revelam uma predominância das condições de insuficiência precária e de omissão em relação às considerações sobre impactos ambientais e sistema de segurança nas apreciações de todas as atividades analisadas. A condição de suficiência em tratamento dos efluentes e gerenciamento de resíduos sólidos só é observada em algumas atividades.

Figura 8 - Critérios apreciados sobre os potenciais impactos dos empreendimentos e as medidas mitigadoras propostas

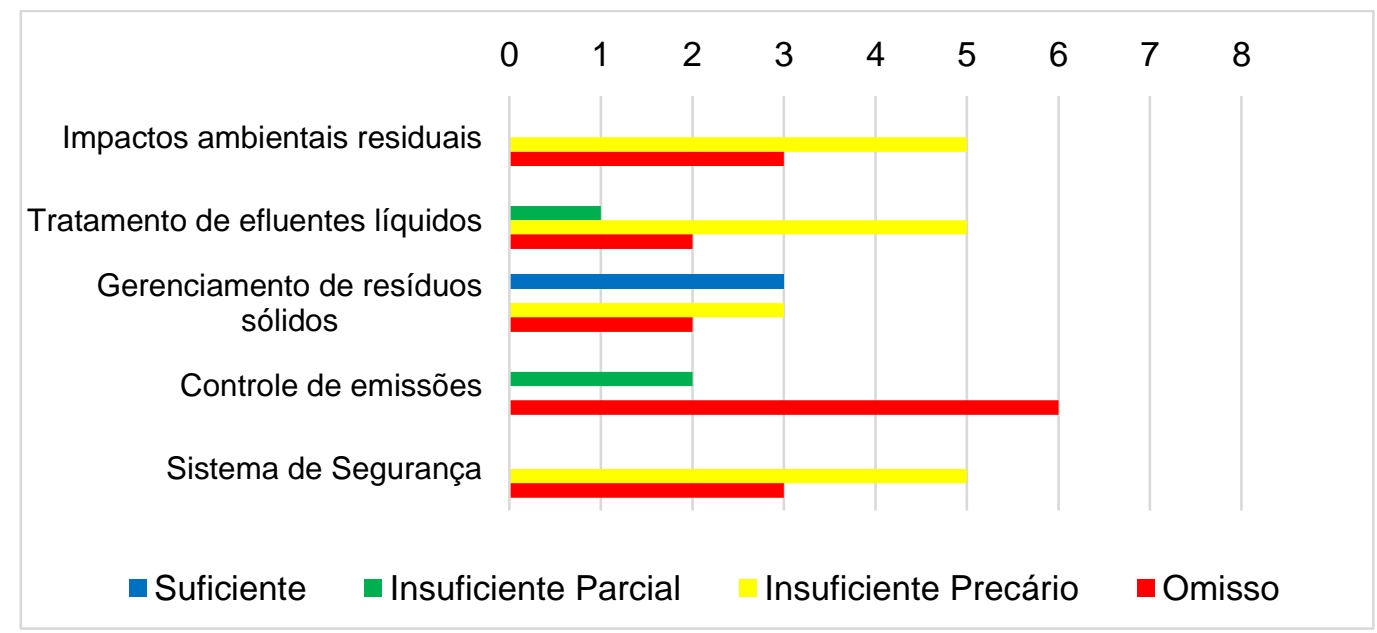

Fonte: os autores.

Embora a legislação vigente (Decreto Estadual no 14.024/2012, Art. 104) (BAHIA, 2012) preconize a determinação de medidas que atendam aos princípios da produção limpa e ecoeficiência, nos roteiros disponibilizados para empreendimentos industriais, apenas nos 
municípios de Feira de Santana e Lauro de Freitas foram solicitadas informações quanto aos prováveis aproveitamentos de subprodutos e resíduos gerados. Os pareceres limitam-se a mencionar as propostas e medidas apresentadas pelo próprio requerente em relação ao reúso de água nos processos produtivos e ao reaproveitamento ou reciclagem dos resíduos sólidos gerados.

Outras omissões relevantes foram constatadas nos demais aspectos. Por exemplo, apesar de os requerentes terem apresentado informações sobre o quantitativo de insumos, matérias-primas, água e energia, os pareceres são omissos na apreciação das possibilidades de minimização do consumo da água e energia. Em alguns pareceres, a apreciação realizada limita-se a mencionar a existência de um sistema de tratamento ou de viabilidade de esgotamento sanitário pela concessionária responsável; sem que haja uma análise da adequação do sistema proposto ou sem qualquer esclarecimento sobre as características ou eficiência das soluções adotadas para os efluentes gerados.

Quanto às ações relacionadas ao controle de emissões, tratamento de efluentes e ao gerenciamento de resíduos sólidos apresentadas na figura 8 , percebe-se a predominância de omissão na apreciação dessas medidas mitigadoras. Nos pareceres, é apenas mencionado, resumidamente, que existe algum tipo de controle ou tratamento, geralmente apresentado pelo próprio requerente, mas sem análise conclusiva sobre a sua potencial efetividade. $O$ critério do gerenciamento de resíduos sólidos é o único apreciado com suficiência em 2 (duas) atividades de industriais e 1 (uma) na construção civil. Isso se deve ao fato de o órgão ter à sua disposição os planos de gerenciamento apresentados pelos solicitantes ou pela existência de normas municipais.

Constata-se que as apreciações e abordagens realizadas mostram maior preocupação em verificar se as atividades propõem medidas mínimas de gerenciamento convencionais (típicas de fim de tubo), por exemplo, em relação à destinação para resíduos sólidos, ao tratamento e à destinação para os efluentes líquidos. Isso denota que a possibilidade de indeferimento da licença não é considerada e que a intenção é apenas verificar se existe uma estrutura mínima para que o empreendimento possa ser implantado e se ele pode atender os padrões vigentes de qualidade ambiental. Não se constata nenhuma abordagem visando a uma apreciação preventiva.

Fica evidente que nos pareceres dos órgãos licenciadores há omissão de apreciações sobre o potencial de intervenção ambiental de um empreendimento e sobre as medidas mitigadoras cabíveis, tampouco se estas são possíveis de serem implantadas. A figura 8 torna claro que a avaliação sobre impactos ambientais residuais é uma deficiência determinante nos processos de licenciamento ambiental. Como enfatizado em diversas publicações, Marinho e colaboradores (2012), Machado (2016), Sadler (1996), Agra Filho, (2016), Montaño e Souza, (2008), os deferimentos das licenças devem ser rigorosamente fundamentados na possibilidade de as medidas mitigadoras serem suficientes para a compatibilização dos potenciais impactos com as condições ambientais. $\mathrm{Na}$ perspectiva preventiva, seria ainda relevante que fossem incluídos como critérios de análise a aplicação da melhor tecnologia disponível e os princípios da produção mais limpa e sustentabilidade da atividade.

Nos relatos das entrevistas realizadas sobre os critérios que eles consideravam relevantes e determinantes para deferir ou não uma licença ambiental, os técnicos informaram que a prática existente consistia na análise da documentação exigida, no atendimento à legislação aplicável, na existência de algum impedimento legal ou de restrições ambientais. Assim sendo, os resultados sugerem uma prática restrita à aferição documental associada à inexistência de diretrizes ou de um roteiro que auxilie a análise do técnico, o que compromete a qualidade e efetividade do licenciamento ambiental. Os pareceres dos municípios não possuem um padrão de apreciação satisfatório que conclua quanto à compatibilidade das intervenções propostas com o local selecionado, proporcionando o alcance do objetivo de prevenção e regulação desse instrumento ambiental.

\section{CONCLUSÕES}

Os resultados e considerações destacadas apontam que as práticas do 
licenciamento ambiental nos municípios estudados apresentam fragilidades relevantes nos seus processos. Essas fragilidades são observadas nas informações solicitadas e fornecidas e se refletem nas abordagens e nas apreciações desenvolvidas nos pareceres. Foram identificadas deficiências de informações tanto na caracterização do potencial de intervenção e na caracterização ambiental quanto nos estudos relativos ao potencial de impactos $e$ às medidas mitigadoras propostas

Em relação aos pareceres, constata-se que as apreciações e abordagens realizadas mostram maior preocupação em verificar se há previsão de se adotarem propostas de gerenciamento de problemas e aspectos convencionais típicas de fim de tubo relativos ao controle de efluentes, resíduo ou emissões, e não apresentam considerações quanto à suficiência de informações em relação aos potenciais impactos previstos. A omissão de um critério fundamental nos pareceres, como a avaliação de impactos ambientais, pode ser percebida já na etapa da própria definição pelo órgão ambiental de quais informações deverão ser apresentadas pelo requerente. Pode-se constatar os reflexos dessa indiligência na qualidade dos pareceres, que se revelaram insuficientes ou omitem a análise dos impactos e das medidas mitigadoras. Cabe ressaltar também a inexistência nos municípios estudados de diretrizes ou alguma instrução técnica quanto à apreciação da atividade ou empreendimento proposto e de seus potenciais impactos ambientais.

O licenciamento ambiental, na sua perspectiva preventiva e de promover o ciclo de melhoria contínua, possibilita induzir medidas de gerenciamento comprometidas com as alternativas de prevenção e deve ser aplicado com esse intuito, considerando as tecnologias mais limpas disponíveis. Para que essa intenção se concretize, a análise substantiva torna-se absolutamente indispensável nos pareceres do licenciamento ambiental. Entretanto, os procedimentos seguidos sugerem uma prioridade ou uma abordagem predominantemente direcionada para uma aferição cartorial; e as apreciações realizadas estão voltadas para 0 atendimento aos requisitos normativos básicos estabelecidos na legislação. Pratica-se uma análise procedimental em detrimento de uma análise substantiva de compatibilização do potencial de intervenção do empreendimento ou atividade proposta com as condições de resiliência e vulnerabilidade ambiental do local selecionado.

Tendo em vista que a análise substantiva é uma apreciação imprescindível para se cumprir o propósito preconizado na Constituição Federal (BRASIL, 1988) de se proceder às avaliações prévias das atividades com potencial impacto significativo, o seu descumprimento evidencia uma negligência inadmissível por comprometer a função precípua do licenciamento ambiental. Vale ainda destacar que as normas vigentes da legislação, embora necessárias como algo preliminar para delimitar ou balizar alguns aspectos na apreciação das licenças requeridas, são insuficientes para suprir a avaliação específica de cada condição ambiental da localidade do empreendimento.

Os resultados e discussões desenvolvidas permitem inferir que a prática do licenciamento ambiental nos municípios estudados não está promovendo o seu objetivo de prevenção e controle da degradação ambiental. A aplicação desse importante instrumento de prevenção ambiental tem negligenciado a análise substantiva do potencial de impacto das atividades licenciadas. Outrossim, o licenciamento ambiental, nos processos analisados, não cumpriu o seu papel de promover e exigir práticas e tecnologias com ênfase na produção limpa, de modo a incrementar a ecoeficiência dos processos e reduzir os riscos à qualidade ambiental.

Essas considerações finais, além de confirmarem as fragilidades destacadas por Hofmann (2015), IPEA (2013), Agra Filho (2016), Silva e colaboradores (2014), fornecem elementos marcantes sobre a necessidade de aprimoramento da definição estabelecida na lei complementar no 140/201 do que seja um órgão capacitado. Em definição legal, isso se restringe a um órgão que disponha de "técnicos próprios ou em consórcio, devidamente habilitados e em número compatível com a demanda das ações administrativas" (BRASIL, 2011).

\section{REFERÊNCIAS}

AGRA FILHO, S. S. Oportunidades de aprimoramento do processo de avaliação de impacto ambiental no Estado da Bahia. Revista Brasileira 
de Ciências Ambientais, São Paulo, n. 26, dez. 2012.

Planejamento e gestão ambiental no Brasil: os instrumentos da política nacional de meio ambiente. Rio de Janeiro: Elsevier, 2014.

A análise prévia do licenciamento ambiental: uma reflexão e proposição de inserção da perspectiva da sustentabilidade na apreciação do mérito da viabilidade ambiental. In: CONGRESSO BRASILEIRO DE AVALIAÇÃO DE IMPACTO, 3., 2016, Ribeirão Preto, SP. Anais eletrônicos [...]. Disponível em: <http://avaliacaodeimpacto.org.br/wpcontent/uploads/2019/08/AnaisCBAl1611.pdf>. Acesso em: 20 fev. 2017.

ALMEIDA, M. R. R. et al. P. Aplicação de métodos para revisão da qualidade de estudos de impacto ambiental Revista de Gestão Ambiental e Sustentabilidade, São Paulo, v. 1, n. 2, jul./dic. 2012.

BAHIA. Decreto 14.024, de 06 de junho de 2012. Aprova o Regulamento da Lei no 10.431 , de 20 de dezembro de 2006, que instituiu a Política de Meio Ambiente e de Proteção à Biodiversidade do Estado da Bahia, e da Lei oㅜ 11.612, de 08 de outubro de 2009, que dispõe sobre a Política Estadual de Recursos Hídricos e o Sistema Estadual de Gerenciamento de Recursos Hídricos. Diário Oficial, Poder Executivo, Salvador, BA, 07 jun. 2012. Disponível em: <http://www.sucom.ba.gov.br/wpcontent/uploads/20 15/04/Dec_Estadual_14024_2012.pdf>. Acesso: nov. 2016.

BAHIA. Conselho Estadual de Meio Ambiente. Resolução no 4.327, de 31 de outubro de 2013. Dispõe sobre as atividades de impacto local de competência dos Municípios, fixa normas gerais de cooperação federativa nas ações administrativas decorrentes do exercício da competência comum relativas à proteção das paisagens naturais notáveis, à proteção do meio ambiente e ao combate da poluição em qualquer de suas formas, conforme previsto na Lei Complementar n 140/2011, e dá outras providências. Diário Oficial, Salvador, BA, 03 dez. 2013. Disponível em: <http://www.meioambiente.ba.gov.br/arquivos/File/ GAC/150514Resolucao4327ImpactoLocaLdosMuni cipios.pdf>. Acesso: nov. 2016.

BRASIL. Constituição (1988). Constituição da República Federativa do Brasil. Brasília, DF: Senado, 1988.

BRASIL. Lei no 6.938, de 31 de agosto de 1981 . Dispõe sobre a Política Nacional do Meio Ambiente, seus fins e mecanismos de formulação e aplicação, e dá outras providências. Diário Oficial da União, Poder Legislativo, Brasília, DF, 02 set. 1981. Disponível $<$ https://www2.camara.leg.br/legin/fed/lei/19801987/lei-6938-31-agosto-1981-366135publicacaooriginal-1-pl.html>. Acesso em: out. 2016.

BRASIL. Lei Complementar no 140 de 08 de dezembro de 2011. Fixa normas, nos termos dos incisos III, VI e VII do caput e do parágrafo único do art. 23 da Constituição Federal, para a cooperação entre a União, os Estados, o Distrito Federal e os Municípios nas ações administrativas decorrentes do exercício da competência comum relativas à proteção das paisagens naturais notáveis, à proteção do meio ambiente, ao combate à poluição em qualquer de suas formas e à preservação das florestas, da fauna e da flora; e altera a Lei no 6.938, de 31 de agosto de 1981. Diário Oficial da União, Poder Legislativo, Brasília, DF, 9 dez. 2011. p.1. Disponível em: <http://www.planalto.gov.br/ccivil_03/leis/LCP/Lcp14 0.htm>. Acesso em: out. 2016.

BRASIL. Tribunal de Contas da União. Cartilha de licenciamento ambiental. Tribunal de Contas da União. Colaboração do Instituto Brasileiro do Meio Ambiente e dos Recursos Naturais Renováveis. 2. ed. Brasília: TCU, 4ํㅗ Secretaria de Controle Externo, 2007.

FARIAS, T. Licenciamento Ambiental: aspectos teóricos e práticos. 4. ed. Belo Horizonte: Fórum. 2015.

HOFMANN, R. M. Gargalos do licenciamento ambiental federal no Brasil. Salvador: Consultoria Legislativa da Câmara dos Deputados, 2015. (Estudos das Consultorias Legislativa e de Orçamento e Fiscalização Financeira da Câmara dos Deputados).

INSTITUTO DE PESQUISA ECONÔMICA APLICADA. Licenciamento ambiental para o desenvolvimento urbano: avaliação de instrumentos e procedimentos. Rio de Janeiro: Ipea, 2013.

KIPERSTOK, A. et al. Prevenção da Poluição. Brasília: Senai/DN, 2002. 290 p.

MACHADO, P. A. L. Direito Ambiental Brasileiro. 24. ed. São Paulo: Malheiros, 2016. 1408 p.

MARINHO, M. M. O. et al. Propostas de aprimoramento do licenciamento ambiental no estado da Bahia: a etapa da licença de implantação. Magistra, Cruz das Almas, vol. 22, julho 2010. 
(Edição especial referente ao I Congresso Baiano de Engenharia Sanitária e Ambiental).

MARINHO, M. M. O. et al. Avaliação de Impacto Ambiental como Instrumento de Estímulo à Produção Limpa: Desafios e Oportunidades no Estado da Bahia. Revista de Gestão Social e Ambiental - RGSA, São Paulo, v. 6, n. 3, p. 129141, set./dez. 2012.

MILARÉ, É. Direito do Ambiente. 7. ed. São Paulo: Revista dos Tribunais, 2011.

MONTAÑO, M.; SOUZA, M. P. A viabilidade ambiental no licenciamento de empreendimentos perigosos no Estado de São Paulo. Engenharia Sanitária e Ambiental, v.13, n. 4, out/dez 2008.

MONTAÑO, M. et al. Revisão da qualidade de estudos de impacto ambiental de pequenas centrais hidrelétricas. Holos Environment, v. 14, n. 1, p. 114, 2014.

NASCIMENTO, T. R. S; FONSECA, A. Opinião de gestores e analistas ambientais sobre a municipalização do licenciamento ambiental: uma sondagem nacional. In: CONGRESSO BRASILEIRO DE AVALIAÇÃO DE IMPACTOS, 3., 2016, Ribeirão Preto, SP. Anais eletrônicos [...]. Disponível em: $<$ http://avaliacaodeimpacto.org.br/wpcontent/uploads/2019/08/AnaisCBAl1611.pdf>. Acesso em: 20 fev. 2017.

REGANHAN, J. M. et al. O Licenciamento ambiental federal no Brasil: nascimento, evolução e avaliação.
In: MOTTA, D. M.; PÊGO, B. (Org.) Licenciamento ambiental para 0 desenvolvimento urbano: avaliação de instrumentos e procedimentos. Rio de Janeiro: Ipea, 2013. cap. 4, p.113-134.

SADLER, B. Environmental Assessment in a Changing World: Evaluating Practice to Improve Performance. International Study of the Effectiveness of Environmental Assessment. Final report. Ottawa, Ont.: International Association for Impact Assessment: Canadian Environmental Assessment Agency, 1996. Disponível em: <https://unece.org/DAM/env/eia/documents/StudyEf fectivenessEA.pdf>. Acesso em: out. 2016.

SÁNCHEZ, L. E. Avaliação de Impacto Ambiental: Conceitos e Métodos. São Paulo: Oficina de Textos, 2008.

SCHERER, M. Análise da qualidade técnica de estudos de impacto ambiental em ambientes de Mata Atlântica de Santa Catarina: abordagem faunística Biotemas, Florianópolis, 24 (4), p. 171 181, dez. 2011.

SILVA, B. M. P.; CAVALCANTI, P. M. P. S.; RODRIGUES, M. G.: ALMEIDA, J R. Análise do processo de licenciamento ambiental no estado do rio de janeiro. Revista Internacional de Ciências, Rio de Janeiro, v. 4, n. 2, jul./dez., 2014.

STRUCHEL, A. C. O. Licenciamento Ambiental Municipal. São Paulo: Oficina de Textos, 2016. 